\title{
Relevant prior knowledge moderates the effect of elaboration during small group discussion on academic achievement
}

\author{
Floris M. Van Blankenstein • Diana H. J. M. Dolmans • \\ Cees P. M. Van der Vleuten • Henk G. Schmidt
}

Received: 21 December 2010/Accepted: 25 June 2012/Published online: 10 July 2012

(C) The Author(s) 2012. This article is published with open access at Springerlink.com

\begin{abstract}
This study set out to test whether relevant prior knowledge would moderate a positive effect on academic achievement of elaboration during small-group discussion. In a $2 \times 2$ experimental design, 66 undergraduate students observed a video showing a smallgroup problem-based discussion about thunder and lightning. In the video, a teacher asked questions to the observing participants. Participants either elaborated by responding to these questions, or did not elaborate, but completed a distraction task after each question. They received either relevant or irrelevant prior knowledge before the discussion. After the discussion, all participants studied a text about thunder and lighting and completed immediate and delayed-recall tests for this text. Elaboration had no main effect on recall, but there was a significant interaction effect between relevant prior knowledge and elaboration. The results suggest that elaboration is helpful for students with more prior knowledge, but harmful for students with less prior knowledge.
\end{abstract}

Keywords Collaborative learning - Discussion - Elaboration · Explanation · Prior knowledge $\cdot$ Problem-based learning $\cdot$ Small group learning

\section{Introduction}

Collaborative learning is widely applied in education, but as yet little is known about the cognitive processes that make it successful. This lack of knowledge results from the complexity of collaborative settings, in which many factors can influence learning. This study focused on a specific instructional format, problem-based learning (PBL), and used a controlled experimental design to reduce the number of confounders to final learning outcomes. The first aim was to examine the effect of elaboration during small-group

F. M. Van Blankenstein · D. H. J. M. Dolmans $(\bowtie) \cdot$ C. P. M. Van der Vleuten

Department of Educational Research and Development, Maastricht University, P.O. Box 616, 6200 MD Maastricht, The Netherlands

e-mail: d.dolmans@maastrichtuniversity.nl

H. G. Schmidt

Erasmus University Rotterdam, P.O. Box 1738, Woudestein, 3000 DR Rotterdam, The Netherlands 
discussion on the recall of the information studied after the discussion. The second aim was to evaluate relevant prior knowledge as a moderator for the effect of elaboration on recall.

\section{Cognitive elaboration in collaborative learning}

Cognitive theories for collaborative learning stress the importance of cognitive elaboration (O'Donnell 2006; Slavin et al. 2003). Collaboration can stimulate elaboration because students process information more deeply when they interact with each other. Elaboration can be defined as the generation of meaningful new relations between prior knowledge, or between prior knowledge and new information (Wittrock 1992). A theoretical expectation is that it leads to an enriched knowledge base with more interconnections. Inside this enriched knowledge base, information should be better retained (Hamilton 2004; Reder 1980).

Research has indeed shown that students remember more information from textual materials when they use elaboration techniques during self-study (Dansereau et al. 1979; Mayer 1980; Pressley et al. 1987, 1988). In collaborative learning settings, it has been shown that students recall more information from textual materials after engaging in elaborative activities, such as summarizing text passages and detecting errors and omissions in the resulting summaries (Larson et al. 1985; McDonald et al. 1985; O'Donnell 1996; O'Donnell et al. 1985; Rewey et al. 1989; Spurlin et al. 1984). This usually promoted recall of the studied information, especially for those who summarized the text (Spurlin et al. 1984). Students can thus elaborate during collaboration by explaining some learning materials to other students (Slavin et al. 2003). Research has shown that the frequency of elaborative explanation during small-group discussion correlates positively with learning achievement (Van Boxtel et al. 2000; Webb 1989; Webb et al. 2008). According to some, explanation to others challenges the explainer to generate new relations and form new perspectives (Bargh and Schul 1980). The explainer may detect gaps in his or her own knowledge and use explanation to fill in these gaps (Webb et al. 1995). In other words, explanation to others can provoke elaboration.

\section{Cognitive elaboration in PBL}

PBL is a collaborative learning format that comes in many forms (Lloyd et al. 1998). The present experiment adopted the definitions of PBL by Schmidt et al. (2009). These authors describe PBL as a process in which students try to explain several phenomena that belong to a real-world scenario (i.e. the problem). The group discussion forms the basis of subsequent self-study. After this self-study, students gather again to report their findings. In other words, a learning cycle starts with a problem-based discussion and ends with a reporting phase after self-study (also see Hmelo-Silver 2004).

During a problem-based discussion, students can activate their prior knowledge, reason together, build theories and experience cognitive conflict (Dolmans and Schmidt 2006). Research has shown that a problem-based discussion can improve the recall of a text studied after the discussion (De Grave et al. 2001; Schmidt 1984; Schmidt et al. 1989). Schmidt et al. (1989) let students discuss a problem that described why a blood cell swells in pure water and shrinks in salt water. After the discussion, they individually studied a text about osmosis and diffusion, which explained the underlying mechanisms for the phenomena in the blood cell problem. In a control group, students discussed a problem about a different topic and then read the osmosis and diffusion text. Students who discussed the blood cell problem recalled more information from the text than students who discussed the problem about the different topic. 
Although a problem-based discussion seems to be able to improve recall, it is not clear which cognitive activities are responsible for this effect. Considering the already mentioned findings from collaborative learning, one would expect that elaboration (by explanation to others) is an important activity that fosters learning during the discussion. Some studies signify that PBL students retain more knowledge over time than students in lecture-based programs (Capon and Kuhn 2004; Dochy et al. 2003; Eisenstaedt et al. 1990; Tans et al. 1986). This might suggest that PBL indeed promotes elaboration, because elaboration should lead to an increase in deep processing and therefore improve the retention of knowledge (Reder 1980). However, one study reported that there was no positive correlation between the number of explanations students generated during a problem-based discussion and their recall from subsequent self-study (Moust et al. 1987). More empirical data is thus needed to support the hypothesis that elaboration during problem-based discussion promotes achievement. The present experiment set out to do this, by testing the effect of elaboration during the problem-based discussion on recall of information studied after the discussion.

The interaction between prior knowledge and elaboration

Prior knowledge seems to guide what students recall from new information. This can be illustrated by experiments in which students activated relevant prior knowledge before self-study (Machiels-Bongaerts et al. 1995; Peeck 1982; Pressley et al. 1990; Wetzels et al. 2011). Machiels-Bongaerts et al. let students activate prior knowledge about a fishery policy of the European Union and then presented them with a text about this policy. The text also contained information that was related to the policy (i.e. increased unemployment due to the policy and alternative income sources) and information that was unrelated to the policy. A control group activated information about an irrelevant topic. Students who activated prior knowledge about the policy recalled more information from the text than the control group. More specifically, they did not only recall more about the policy, but also about the related information. Prior knowledge activation thus seemed to improve the recall of information from the text. In addition, it especially improved the recall of information that either corresponded with, or was related to, the activated prior knowledge.

Likewise, Wetzels et al. (2011) found that prior knowledge activation improved achievement on learning tasks that were related to the activated prior knowledge. The investigators proposed that prior knowledge activation served a 'stage-setting function'. The activated prior knowledge 'set the stage' for new learning and therefore improved the learning of new information that was related to the activated knowledge. A problem-based discussion might serve a similar stage-setting function. Schmidt et al. (1989) proposed that problem-based discussion leads to a shared mental model of the problem, which will facilitate the study of new information that relates to the problem.

Prior knowledge has also been shown to moderate the positive effect of elaboration on the learning of facts (Willoughby et al. 1993; Woloshyn et al. 1992). That is, students who elaborated on facts, by generating a reason why these facts were true, recalled more of these facts when they had more prior knowledge.

Since problem-based discussions allow students to activate and elaborate on their prior knowledge (Schmidt 1993), it may be worth studying elaboration in combination with higher or lower amounts of prior knowledge. In some versions of PBL, students receive a limited amount of knowledge at the start of the group meeting, just before the problembased discussion commences (Hmelo-Silver and Barrows 2008). The present experiment 
followed this example, by providing research participants with a limited amount of information before they entered a small-group discussion.

\section{Difficulties with research on collaborative learning}

Research on small-group learning has to contend with the fact that group processes are highly dynamic and therefore create many variables that potentially affect learning outcomes. Since experimental interventions often take place at the group level, it is difficult to determine which specific cognitive processes promote achievement. For example, the amount of elaboration during a group discussion may depend on the cognitive ability level of individual group members (Webb et al. 1998). From a research perspective, it might be valuable to rule out these random influences from the group on learning. This will allow investigators to study independent variables more precisely, without confounding variables that create experimental noise. It seems that the group process must be standardized in order to accomplish this. The present experiment aimed at doing this by creating a video recording of a problem-based discussion supervised by a teacher. This video was shown to individual research participants in a psychological laboratory. This new method facilitated the testing of independent variables, while omitting other influences from the group's process. More about this will follow in the "Method" section.

\section{Summary and hypotheses}

In summary, collaborative learning needs more empirical evidence for the hypothesis that elaboration is responsible for improved academic achievement. Elaboration may be moderated by the amount of prior knowledge students have before they enter a small-group discussion. A problem is that complex group processes produce many potential influences on final learning outcomes. This makes it difficult to study the interaction between elaboration and prior knowledge independently from other factors. Therefore, the current experiment ensured that all research participants were exposed to the same small-group discussion. For this purpose, a video recording of the discussion was made and presented to the participants. There were two hypotheses: firstly, elaboration during the group discussion was expected to improve the participants' recall of the information that they studied after the discussion; secondly, elaboration was expected to improve recall when participants received relevant prior knowledge before the group discussion. In other words, the second hypothesis was an interaction effect between prior knowledge and elaboration on recall.

\section{Method}

\section{Participants}

Participants were 66 university students who had chosen a secondary school learning trajectory that focused on the social sciences. In the Netherlands, students progress through secondary school from age 12 until 18 . Some of them follow a curriculum that prepares them for university education. These students can choose between four paths, two of which are science-oriented and two focused on the social sciences. Only participants with backgrounds in the social sciences were selected for this study, because they were likely to have less prior knowledge about the study topic, which was science-oriented. They came from study programs in law (46), economics and business administration (7), psychology 
(5), health sciences (2), art (1) and arts and social sciences (1). Their mean age was 20.93 $(\mathrm{SD}=2.22)$. They were selected with advertisements and by active recruitment. All participants were familiar with PBL and received a financial compensation for their participation.

\section{Materials}

\section{Study materials and tests}

Twenty-one sentences were written about thunder and lightning and 21 sentences about seismographic activity. The sentences about thunder and lightning were presented to half of the participants as relevant prior knowledge for a problem-based group discussion. The sentences about seismographic activity, which were not relevant for the discussion, were presented to the other half of the participants. Two sentence-completion tests were devised, one for the thunder and lightning sentences and one for the seismographic activity sentences. These tests presented the sentences in random order, each sentence lacking one or several key words. Participants had to fill in these missing words. The sentences about thunder and lightning can be found in Table 1 and the sentences about seismographic activity in Table 2. The missing words in the sentence-completion test are underlined.

A problem from a PBL teacher-training program was adopted for the small-group discussion. Table 3 shows the problem, which described a thunder and lightning storm during a warm summer day in 102 words. It contained several phenomena that were related to thunder and lightning, such as warm temperatures, thunderclouds and rain drops.

A study text about thunder and lightning was written, which provided relevant new information about the problem. This text was offered after the small-group discussion and explained in 1,104 words how lightning is created and what a person should do during a thunderstorm. For example, one paragraph elaborated on the first, second and third thunder

Table 1 Sentences to provide relevant prior knowledge before the small group discussion

1. Thunderclouds are very high clouds that reach till the upper levels of the atmosphere

2. During the summer, warm air comes in our direction from the south of France

3. All kinds of warm and cold air currents take place in the atmosphere

4. A difference in electrical charge within a thundercloud causes lightning

5. The thundercloud is charged positively at the top and negatively at the bottom

6. The thundercloud contains water drops and hail stones

7. During thunder and lightning, the electrical charges of the cloud and the earth differ

8. The earth is charged positively compared to the cloud

9. Lightning is an electrical current

10. Just before the lightning bolt, there is a stepped leader

11. Sometimes, you can see a small flash just before the lightning bolt

12. Thunder is a loud bang you hear after the lightning bolt

13. A lightning bolt is incredibly hot

14. Lightning prefers to strike on points that stick out from their surroundings

15. Lightning prefers to strike on points that conduct electricity well

16. When you are struck by lightning, an electrical current runs through your body

17. Even at a reasonable distance from the point where lightning strikes, you can be in danger

18. During thunder and lightning, you should go inside and close all windows and doors

19. When you are outside during lightning, you should find shelter

20. During lightning, you are safe inside a car

21. When you are in an open field during lightning and cannot find any shelter, you should squat with your feet against each other 
Table 2 Sentences to provide irrelevant prior knowledge before the small group discussion

1. An earthquake is a vibration of the earth's crust

2. Sometimes, the earth's mantle underneath the crust shakes as well

3. The vibration is usually caused by fault lines

4. A well-known fault line is the San Andreas Fault in California

5. The earth exists of different layers

6. The outer layer of the earth is called the crust

7. The crust is made up of tectonic plates

8. Tectonic plates are large pieces of earth that 'float' on the mantle underneath

9. Two plates rubbing against each other cause a series of vibrations

10. The crust consists of magma

11. Magma is a red hot, syrupy mass

12. Magma rises to the surface during an earth quake

13. Underneath the mantle lies the earth's core

14. The core is the center of the earth

15. The core is an extremely hot sphere

16. The place where plates drift against each other is called the hypocenter

17. The hypocenter's depth can range from 60 to several hundreds of kilometers

18. The place above the hypocenter on the earth's surface is called the epicenter

19. The epicenter of an earthquake can also lie at the bottom of the sea

20. An earthquake under the sea causes a tsunami

21. A seismograph is a sling that registers movements in the crust

Table 3 Problem used in the video of the small group discussion

You are staying with your family in a vacation home in a hilly area. This morning, you and your smaller brother got up early and went into the hills with your bicycles. It turned out to become a hot, humid summer day. In the afternoon, dark thunderclouds appeared in the sky. Suddenly, you see lightning bolt dashing towards the earth. A few seconds later, it is followed by a rattling thunderclap. Soon afterwards, it starts pouring out of the sky. When your brother tries to seek shelter under a group of trees, you immediately pull him away from underneath these trees, into the open field. There, you tell him to squat.

and lightning sentence, which stated that (1) thunderclouds are very high; (2) warm air from the south of France enters the Netherlands during the summer; and (3) the atmosphere contains warm and cold air currents. Below is an excerpt from this paragraph, which elaborates on the three sentences by describing one situation in which air currents lead to thunder storms. Table 4 produces an excerpt from the study text.

Ten open-ended questions were devised to test how much information participants recalled from the study text. These questions were used for an immediate and a delayed posttest. The question belonging to the text excerpt in Table 4 was:

Describe the two situations in which air currents cause thunder and lightning during the summer.

Table 4 Excerpt from the study text offered after the video

In one situation, the air rises in the atmosphere during a warm period in the south of France. This causes a low pressure area. Warm air is lighter than cold air and therefore it rises. This rising air contains vaporized water, which forms clouds. Because the air rises quickly, these clouds stretch and become very high thunder clouds. The thunderclouds drift in our direction [i.e. the Netherlands] on a wind from the south. 


\section{Small-group discussion}

A video of a small-group discussion was recorded with a Sony DCR VX2000e video camera in a room where PBL group meetings were usually held. In the video, four students discussed the problem about thunder and lightning. The students tackled various issues related to thunder and lightning, as exemplified in one dialogue between two of the four students:

S: "What I don't understand, is how this thundercloud-thing works."

J: "I am not telling you I fully understand this, but... I think there is a difference in electrical charge inside a cloud... Right?" [Looks puzzled to the others.]

During the recording session, eight scenes with a teacher were shot as well. The teacher asked questions into the camera, directed to the observer of the video. These questions encouraged the observer to explain the complex process of thunder and lightning, using the phenomena in the problem. They were specifically designed to relate concepts from the thunder and lightning sentences with each other and with the problem. Furthermore, they always followed a part of the discussion that led up to the question. So, for example, the above-mentioned part of the discussion was followed by this question from the teacher:

In a cloud, there are many currents of air. The cloud also contains water drops and hailstones. But what happens then? How can a difference in electrical charge come about within a cloud?

In this example, the teacher first referred back to the third and sixth sentence about thunder and lightning, which stated that (1) warm and cold air currents take place in the atmosphere; and (2) a thundercloud contains water drops and hailstones. She then asked the viewer to relate these two principles with electrical charges inside a cloud, which relates to sentences 4 ("a difference in electrical charge within a thundercloud causes lightning") and 5 ("the thundercloud is charged positively at the top and negatively at the bottom"). In other words, the question stimulated the generation of new relationships between prior knowledge from the sentences.

\section{Procedure}

Figure 1 shows a flow chart of the procedure. The experiment used a $2 \times 2$ design with elaboration (yes/no) and relevant prior knowledge (yes/no) as independent variables. Participants were randomly assigned to cubicles inside a research lab. Each cubicle contained a 19-inch flat screen, at a reading distance of approximately $70 \mathrm{~cm}$, showing one of the four experimental treatments. Headphones were provided for each participant. Before they entered the research lab, we explained to participants that this was a study of PBL in which they would be exposed to a PBL simulation. All further instructions were given on the screen.

Participants in the elaboration with prior knowledge condition $(n=19)$ studied the thunder and lightning sentences and answered the teacher's elaborative questions during the discussion. Their instructions were that they would participate in a problem-based discussion. During the discussion, a teacher would ask them some questions. They could use information from the sentences and their own ideas to answer these questions. Specifically, the instructions for answering the questions were: (1) write the first thing that comes to mind; (2) write as much as you can come up with; (3) write as many new ideas as 


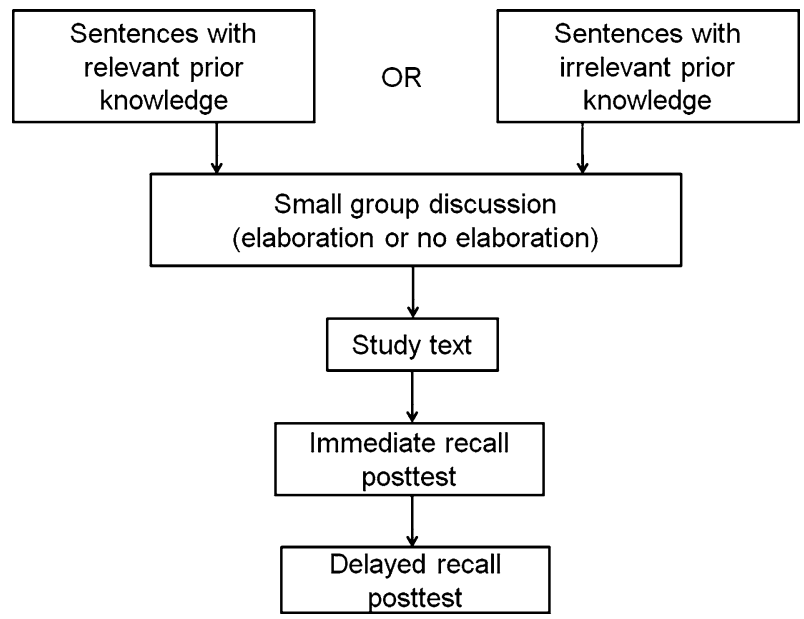

Fig. 1 Flowchart of the experimental procedure

possible; (4) keep writing until you can think of no more ideas; (5) write whole sentences; (6) do not revise your writings.

Participants in the elaboration with prior knowledge condition were also told that they would be introduced to the group first and practice the answering of questions. Upon receiving the instructions, they read each sentence at their own pace. They could continue to a next sentence by hitting the spacebar button. After the last sentence, they completed the sentence-completion test. They then observed the introductory scene, which introduced the students and the teacher by name. Following this, they practiced the procedure by watching a short discussion about an irrelevant subject (i.e. why water comes out of a tap) and answering a question from the teacher about this topic.

Subsequently, the problem appeared on the screen for $1 \mathrm{~min}$ and the discussion started. After each question, a blank screen with a text field appeared. Participants could type their answer in this text field and continue with the discussion by clicking a button on the screen. They spent an average of $1311.63 \mathrm{~s}(\mathrm{SD}=438.35)$, or $21 \mathrm{~min}$ and $51.63 \mathrm{~s}$ on this task. After the discussion, the study text appeared on the screen for $15 \mathrm{~min}$. Participants studied this text and were told beforehand that a test would follow after $15 \mathrm{~min}$. A time bar at the top of the screen indicated how much time was left. After this period, the ten open-ended questions appeared on the screen and participants completed these as the immediate posttest. Three weeks later, they returned to the research lab and completed these questions again as the delayed posttest.

In the elaboration without prior knowledge condition $(n=18)$, participants followed the same procedure as in the elaboration with prior knowledge condition, but this time they read the 21 sentences and completed the sentence-completion test about seismographic activity. Contrary to the procedure in the elaboration with prior knowledge condition, they were not told that information from the sentences was needed to answer questions by a teacher. Thus, participants who elaborated without prior knowledge did not receive the relevant prior knowledge, but did elaborate by answering the teacher's questions. They spent an average of $1225.61 \mathrm{~s}(\mathrm{SD}=674.31)$, or $20 \mathrm{~min}$ and $25.61 \mathrm{~s}$ on the discussion.

In the no elaboration with prior knowledge condition $(n=14)$, participants followed the same procedure as in the elaboration with prior knowledge condition, but this time they 
received a distraction task after each question by the teacher. These tasks were games of tetris. So while the elaboration with prior knowledge condition elaborated by answering the teacher's questions, the no elaboration with prior knowledge condition played tetris during these intervals. Distraction tasks were used because there are indications that students elaborate considerably without voicing their thoughts during problem-based discussions (De Grave et al. 1996). The distraction tasks were thus included to prevent silent elaboration. The time spent on the discussion was based on the average time spent by the elaboration with prior knowledge condition $(21 \mathrm{~min}$ and $51.63 \mathrm{~s})$.

Since both conditions received the relevant prior knowledge about thunder and lightning, it was checked whether both groups had the same level of prior knowledge. A $t$ test did not show a significant difference in number of errors on the sentence-completion test, $t(1,33)=.71, p=.48$.

In the no elaboration without prior knowledge condition $(n=15)$, participants performed the same tasks as in the elaboration without prior knowledge condition, but they also received the distraction tasks instead of answering the teacher's questions. Therefore, they neither received relevant prior knowledge, nor did they elaborate during the discussion. Their time spent on the discussion was based on the average time spent by the elaboration without prior knowledge condition (20 min and $25.61 \mathrm{~s}$ ).

Analyses

The posttest results were segmented into idea units (Mayer 1985). Two coders, unaware of each participant's experimental treatment, performed this activity. An idea unit typically describes one action or event and was defined as a unit that contained one subject-verb clause. Both coders initially segmented the results of two randomly selected participants. The inter-rater reliability was calculated from the perspective of coder 1 , who segmented the smallest total number of idea units. The number of agreements between coder 1 and 2 was divided by this total number, resulting in an agreement percentage of $86.82 \%$. Differences were discussed until consensus was reached. Thereafter, both coders independently segmented the remaining posttest results.

In order to determine how much was remembered from the text, the idea units from the posttest results were matched with idea units from the study text. Therefore, coder 1 segmented the study text into idea units and numbered each unit. Then, coder 1 discussed the applicability of the resulting segmented text with coder 2 . This resulted in some changes in the segmented text, which was subsequently used as an answer key for scoring the test results. The segmented results were coded with Multiple Episode Protocol Analysis (MEPA) by looking for matches between idea units from the posttests and the study text. Each match was assigned the number of the idea unit from the study text and awarded one point. Points were added up to create a total score for each participant. The inter-coder reliability was calculated in MEPA with Cohen's Kappa $(\kappa)$. Values under .40 signify poor reliability, values between .40 and .75 intermediate to good reliability, and values above .75 indicate excellent reliability. For this purpose, each coder matched the idea units from two randomly selected results (one immediate and one delayed posttest result) with the idea units from the study text. On a first try, $\kappa$ was .54 , whereupon the two coders discussed their differences. On the next try, with two new randomly selected test results (one immediate and one delayed posttest result), $\kappa$ reached .75 , a value on the boundary between good and excellent reliability. This reliability was deemed sufficient and therefore coders 1 and 2 independently scored the remaining results. 
The final results of the immediate and delayed posttest were analyzed in SPSS 15.0 with analysis of variance (ANOVA), including elaboration (yes/no) and relevant prior knowledge (yes/no) as independent variables. The measure for the effect size was $\eta^{2}$. For $\eta^{2}$, the indication for a small effect is .01 , for a medium effect .06 , and for a large effect .14 (Cohen 1988). The ANOVA included pairwise comparisons with Bonferroni correction in order to identify specific between-group differences.

\section{Results}

Figure 2 depicts the scores on the immediate and delayed posttests. The means and standard deviations of the immediate posttest are reported in Table 5. On the immediate posttest, neither elaboration, $F(1,62)=2.36, p=.13, \eta^{2}=.04$ (small effect), nor prior knowledge, $F(1,62)=1.81, p=.18, \eta^{2}=.03$ (small effect), had a significant effect on recall. However, the interaction between elaboration and prior knowledge approached significance, $F(1,62)=3.79, p=.06, \eta^{2}=.06$ (medium effect). The pairwise comparisons demonstrated that participants who elaborated with prior knowledge recalled significantly more from the study text $(M=37.79, \mathrm{SD}=10.44)$ than participants who elaborated without prior knowledge $(M=27.39, \mathrm{SD}=15.92), p=.02$. Pairwise comparisons also revealed that no elaboration without prior knowledge actually led to higher recall $(M=38.40, \mathrm{SD}=11.48)$ than elaboration without prior knowledge $(M=27.39$, $\mathrm{SD}=15.92), p=.02$. Elaboration with prior knowledge $(M=37.79, \mathrm{SD}=10.44) \mathrm{did}$ not improve recall compared to no elaboration with prior knowledge $(M=36.50$, $\mathrm{SD}=12.19), p=.78$.

The results of the delayed posttest are shown in Table 6 . These results again did not reveal an effect by elaboration, $F(1,62)=.69, p=.41, \eta^{2}=.01$ (small effect). In

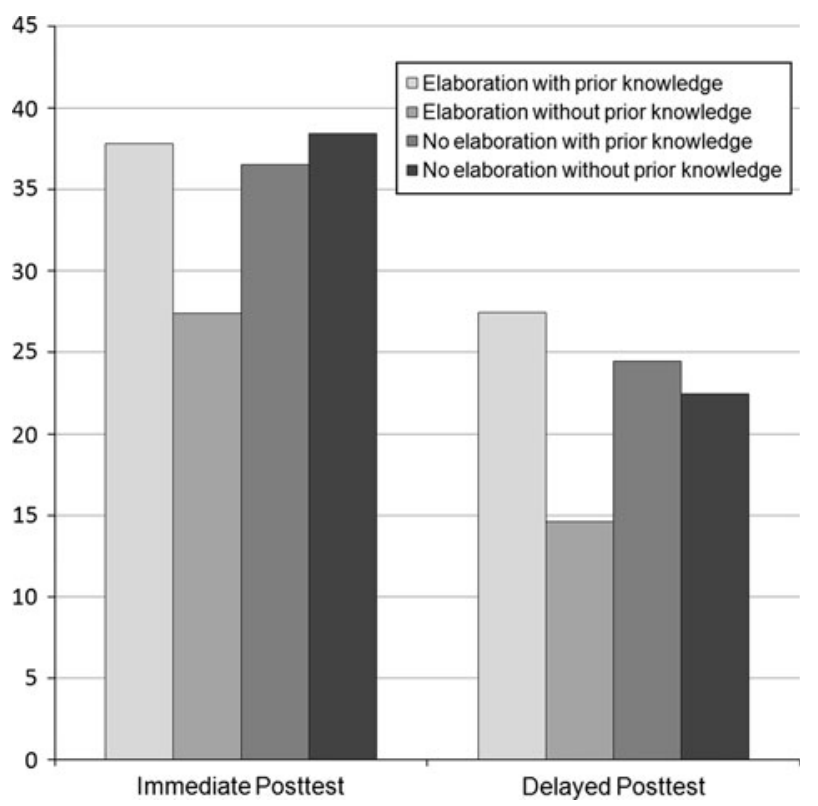

Fig. 2 Mean number of recalled idea units on the immediate and delayed posttest 
Table 5 Mean number of recalled idea units on immediate posttest

\begin{tabular}{|c|c|c|c|c|c|c|c|c|c|}
\hline \multirow[t]{3}{*}{ Relevant prior knowledge } & \multicolumn{9}{|c|}{ Elaboration } \\
\hline & \multicolumn{3}{|l|}{ Yes } & \multicolumn{3}{|l|}{ No } & \multicolumn{3}{|l|}{ Total } \\
\hline & $M$ & SD & $n$ & $M$ & SD & $n$ & $M$ & SD & $n$ \\
\hline Yes & 37.79 & 10.44 & 19 & 36.50 & 12.19 & 14 & 37.24 & 11.05 & 33 \\
\hline No & 27.39 & 15.92 & 18 & 38.40 & 11.48 & 15 & 32.39 & 14.94 & 33 \\
\hline Total & 32.73 & 14.21 & 37 & 37.48 & 11.65 & 29 & 34.82 & 13.26 & 66 \\
\hline
\end{tabular}

Elaboration versus no elaboration: $F(1,62)=2.36, p=.13, \eta^{2}=.04$; prior knowledge * elaboration: $F(1$, 62) $=3.79, p=.06, \eta^{2}=.06$

Table 6 Mean number of recalled idea units on delayed posttest

\begin{tabular}{|c|c|c|c|c|c|c|c|c|c|}
\hline \multirow[t]{3}{*}{ Relevant prior knowledge } & \multicolumn{9}{|c|}{ Elaboration } \\
\hline & \multicolumn{3}{|l|}{ Yes } & \multicolumn{3}{|l|}{ No } & \multicolumn{3}{|l|}{ Total } \\
\hline & $M$ & SD & $n$ & $M$ & SD & $n$ & $M$ & SD & $n$ \\
\hline Yes & 27.42 & 9.23 & 19 & 24.40 & 11.30 & 14 & 26.06 & 10.46 & 33 \\
\hline No & 14.61 & 11.91 & 18 & 22.40 & 11.30 & 15 & 18.15 & 12.11 & 33 \\
\hline Total & 21.19 & 12.32 & 37 & 23.28 & 11.49 & 29 & 22.11 & 11.91 & 66 \\
\hline
\end{tabular}

Elaboration versus no elaboration: $F(1,62)=.69, p=.41, \eta^{2}=.01$; prior knowledge * elaboration: $F(1$, 62) $=4.00, p=.05, \eta^{2}=.06$

contrast, prior knowledge did have an effect on the delayed results, $F(1,62)=7.07$, $p=.01, \eta^{2}=.10$ (medium effect). Furthermore, the interaction between elaboration and prior knowledge was significant, $F(1,62)=4.00, p=.05, \eta^{2}=.06$ (medium effect). Again, the elaboration with prior knowledge condition recalled significantly more $(M=27.42, \mathrm{SD}=9.23)$ than the elaboration without prior knowledge condition $(M=14.61 \mathrm{SD}=11.91), p=.01$. Also, no elaboration without prior knowledge once more led to higher recall scores $(M=22.40, \mathrm{SD}=11.30)$ than elaboration without prior knowledge $(M=14.61 \mathrm{SD}=11.91), p=.04$. And finally, elaboration with prior knowledge $(M=27.42$, SD $=9.23)$ was not more effective than no elaboration with prior knowledge $(M=24.40, \mathrm{SD}=11.30), p=42$.

\section{Discussion}

Interpretation of the findings

This experiment looked at whether elaboration during a problem-based discussion would improve recall from self-study after the discussion. In addition, the moderating influence of prior knowledge on elaboration was examined. There were two hypotheses. Firstly, elaboration was expected to increase recall. The second hypothesis was that prior knowledge would moderate the effect of elaboration on recall, leading to higher recall scores when relevant prior knowledge was present.

The first hypothesis was not supported by the data. This seems to be in line with scant evidence from PBL studies. Moust et al. (1987) found no positive correlation between the 
amount of elaborative explanation during a problem-based discussion and recall from subsequent self-study. Unfortunately, this study did not test a causal relationship between explanation and recall. This also accounts for other reported correlations, which do however tend to show a positive relation between elaborative explanation and achievement (Van Boxtel et al. 2000; Webb 1989; Webb et al. 2008). Some more evidence for a causal relationship between explanation and recall comes from an experiment that showed a positive effect of explaining over listening on recall of textual information (Spurlin et al. 1984). That is, students who verbally summarized a text recalled more from this text than students who listened to the verbal summaries. This suggests that the act of explaining during collaborative discussion fosters achievement. Why then did it not improve recall in the current experiment?

It is possible that a problem-based discussion creates fewer opportunities for contentrelevant explanations than other forms of collaboration. What many forms of collaboration have in common is that the discussion follows or coincides with the acquisition of relevant new information (Dansereau 1988; King et al. 1998; Webb and Farivar 1999). Problembased discussion seems to diverge from this path, as it precedes the acquisition of most relevant prior knowledge. As explained by Schmidt et al. (2009) and Hmelo-Silver (2004), the discussion of the problem forms the basis of new learning. This learning can take place through individual self-study that students perform after the discussion. Hence, they will find most of the new information after they have been discussing the problem. The question is whether a problem-based discussion is focused on relevant knowledge to the same degree as a discussion that succeeds the acquisition of relevant new information. The reporting phase in PBL is such a discussion. During the reporting phase, students report their findings from self-study to each other. This may be a more adequate moment to stimulate elaboration, because students then have already obtained more relevant knowledge about the problem. Therefore, their explanations could be more focused on relevant information, which might help them to remember it better.

The second hypothesis was supported by the findings, because elaboration had a larger effect on recall when participants had relevant prior knowledge before the discussion than when they had no relevant prior knowledge. This is in line with findings from earlier experiments (Willoughby et al. 1993; Woloshyn et al. 1992), which showed elaboration to be more effective when students possessed more relevant prior knowledge about the subject. However, participants without relevant prior knowledge also attained higher recall scores when they did not elaborate than when they elaborated. In addition, elaboration with prior knowledge was not more effective than no elaboration with prior knowledge. This suggests that elaboration with relevant prior knowledge did not improve recall as much as elaboration without prior knowledge impeded it.

What could be an explanation for this? It is possible that the prior knowledge provided before the experiment guided participants' answers to the teacher's questions and thereby 'set the stage' for new learning (Wetzels et al. 2011). It has been shown that students recall more information that relates to their own activated prior knowledge (Machiels-Bongaerts et al. 1995; Peeck 1982; Pressley et al. 1990). In the present experiment, participants who elaborated with relevant prior knowledge may have created a knowledge base that was closely related to the study text they encountered after the discussion. They built this knowledge base through their explanations, as a response to the teacher's questions. In other words, elaboration on the relevant prior knowledge provided good guidance for further self-study. Elaboration with irrelevant prior knowledge may have provided misguidance, confusing participants when they tried to come up with adequate responses to the teacher's questions and impeding their intake of knowledge from the study text. 
Elaboration with irrelevant prior knowledge may also have created more misconceptions than elaboration with relevant prior knowledge. Participants who elaborated without prior knowledge possibly relied more on their own, personal prior knowledge to answer the teacher's questions. Since they lacked a science-oriented background, perhaps this personal knowledge contained misconceptions. As a consequence, they generated more misconceptions during the discussion than their counterparts who received relevant prior knowledge. Misconceptions tend to be persistent, even when students are confronted with contradictory information (Chinn and Brewer 1993). So if the study text contained information that contradicted the framework, the misconceptions may have persisted.

For example, some participants reported a misconception that thunder and lightning was created by friction between clouds during the small group discussion. One of the relevant prior knowledge sentences was: "A difference in electrical charge within a thundercloud causes lightning". This sentence could have repaired the misconception before entering the discussion. Moreover, participants could have used the sentence to generate answers to the teacher's questions, thereby creating a knowledge base that was coherent with the study text. The sentences about seismographic activity could probably not repair the misconception, because they dealt with a different topic. Therefore, it seems likely that these sentences did not aid participants in creating a relevant knowledge base for further self-study.

\section{Limitations and future research}

There are some limitations in this study that need to be considered. First, the experiment used a video recording of a small-group discussion, which may not have represented a reallife situation. However, this drawback came with the benefit of gaining experimental control over the group process. And, although the same degree of interaction and co-construction (Van Boxtel et al. 2000) could not be achieved as in a real-life situation, the activities that were performed during the experiment seemed to resemble those of a natural discussion. That is, the participants in the elaboration conditions provided explanations to other students, as a response to questions by a teacher. They were stimulated to activate prior knowledge and construct new theories, which are common activities in PBL (Dolmans and Schmidt 2006). After the discussion, they performed self-study, which is also part of the PBL process (Hmelo-Silver 2004; Schmidt et al. 2009). With the current research approach, some steps could be made in detecting which elaboration during problem-based discussion has a positive effect on recall.

A second limitation might be that the experimental treatment was too short to cause an effect. A problem-based discussion normally takes more than an hour (Schmidt et al. 2009) and students can discuss one problem for up to two hours, distributed over two meetings (Hmelo-Silver and Barrows 2008). In the present experiment, the discussion only took approximately $20 \mathrm{~min}$. Considering findings that collaborative learning is more effective when the collaboration contains more elaboration episodes (O'Donnell et al. 1985), there is a possibility that the main effect of elaboration was attenuated by the brief period for discussion. Nonetheless, it can also be argued that participation was more active than normal, as students would not usually be addressed by a teacher as frequently as they were in the present experiment. Participants in the two elaboration conditions were activated eight times by the teacher. The question remains whether more elaboration episodes during the discussion will improve subsequent learning.

Future research could thus check whether adding elaboration episodes yields a larger effect. Furthermore, it could investigate whether the ideas generated during the discussion 
lead to the construction of a contextual framework that influences what and how much can be recalled from self-study. If the discussion creates a framework that is relevant for selfstudy, perhaps more is remembered from it. As such, problem-based discussion may be a better preparation for future studying when the ideas emerging during the discussion are more related to subsequent self-study. It might also be interesting to test the effect of misconceptions on recall. Misconceptions may have a negative impact on the learning and recall of subsequently studied information. In contrast, correct or plausible conceptions could have a positive influence on learning. If this is true, problem-based discussion might be a better preparation for new learning when students produce fewer misconceptions during the discussion.

\section{Implications for practice}

The present findings may have some implications for educators in collaborative learning. It is important that a problem-based discussion fits well with the students' prior knowledge. Therefore, it may be important to provide students with some relevant prior knowledge before they enter the discussion. In some versions of PBL, students receive a limited amount of information at the beginning of the group session, just before they start a problem-based discussion (Hmelo-Silver and Barrows 2008). This information should only contain loose concepts, since students need to generate new connections between these concepts themselves, by means of the discussion. Lacking some basic level of relevant prior knowledge may actually be detrimental for future learning, as the present results indicate.

The PBL teacher can also help students to use their prior knowledge in the right way. For example, the teacher can ask directive questions which point more directly to the relevant concepts students need to recall from their self-study after the discussion (Budé et al. 2009). By doing this, the teacher may retrieve relevant prior knowledge from the students. So, in summary, teachers might improve students' recall from self-study by offering them some relevant prior knowledge before the discussion and asking questions during the discussion to retrieve this knowledge.

Open Access This article is distributed under the terms of the Creative Commons Attribution License which permits any use, distribution, and reproduction in any medium, provided the original author(s) and the source are credited.

\section{References}

Bargh, J. A., \& Schul, Y. (1980). On the cognitive benefits of teaching. Journal of Educational Psychology, 72(5), 593-604.

Budé, L., Imbos, T., Van der Wiel, M., Broers, N., \& Berger, M. (2009). The effect of directive tutor guidance in problem-based learning of statistics on students' perceptions and achievement. Higher Education, 57(1), 23-36.

Capon, N., \& Kuhn, D. (2004). What's so good about problem-based learning? Cognition and Instruction, 22(1), 61-79.

Chinn, C. A., \& Brewer, W. F. (1993). The role of anomalous data in knowledge acquisition: A theoretical framework and implications for science instruction. Review of Educational Research, 63(1), 1-49.

Cohen, J. (1988). Statistical power analysis for the behavioral sciences (2nd ed.). Hillsdale, NJ: Erlbaum.

Dansereau, D. F. (1988). Cooperative learning strategies. In C. E. Weinstein, E. T. Goetz, \& P. A. Alexander (Eds.), Learning and study strategies: Issues in assessment, instruction, and evaluation (pp. 103-120). San Diego, CA: Academic Press. 
Dansereau, D. F., Collins, K. W., McDonald, B. A., Holley, C. D., Garland, J., Diekhoff, G., et al. (1979). Development and evaluation of a learning strategy training program. Journal of Educational Psychology, 71(1), 64-73.

De Grave, W. S., Boshuizen, H. P. A., \& Schmidt, H. G. (1996). Problem based learning: Cognitive and metacognitive processes during problem analysis. Instructional Science, 24(5), 321-341.

De Grave, W. S., Schmidt, H. G., \& Boshuizen, H. P. A. (2001). Effects of problem-based discussion on studying a subsequent text: A randomized trial among first year medical students. Instructional Science, 29(1), 33-44.

Dochy, F., Segers, M., Van den Bossche, P., \& Gijbels, D. (2003). Effects of problem-based learning: A meta-analysis. Learning and Instruction, 13(5), 533-568.

Dolmans, D. H. J. M., \& Schmidt, H. G. (2006). What do we know about cognitive and motivational effects of small group tutorials in problem-based learning? Advances in Health Sciences Education, 11(4), 321-336.

Eisenstaedt, R. S., Barry, W. E., \& Glanz, K. (1990). Problem-based learning: Cognitive retention and cohort traits of randomly selected participants and decliners. Academic Medicine, 65, Suppl.(9), 11-12.

Hamilton, R. J. (2004). Material appropriate processing and elaboration: The impact of balanced and complementary types of processing on learning concepts from text. British Journal of Educational Psychology, 74(2), 221-237.

Hmelo-Silver, C. E. (2004). Problem-based learning: What and how do students learn? Educational Psychology Review, 16(3), 235-266.

Hmelo-Silver, C. E., \& Barrows, H. S. (2008). Facilitating collaborative knowledge building. Cognition and Instruction, 26, 48-94.

King, A., Staffieri, A., \& Adelgais, A. (1998). Mutual peer tutoring: Effects of structuring tutorial interaction to scaffold peer learning. Journal of Educational Psychology, 90(1), 134-152.

Larson, C. O., Dansereau, D. F., O’Donnell, A. M., Hythecker, V. I., Lambiotte, J. G., \& Rocklin, T. R. (1985). Effects of metacognitive and elaborative activity on cooperative learning and transfer. Contemporary Educational Psychology, 10(4), 342-348.

Lloyd, J., Margetson, D., \& Bligh, J. G. (1998). Problem-based learning: A coat of many colours. Medical Education, 32(5), 492-494.

Machiels-Bongaerts, M., Schmidt, H. G., \& Boshuizen, H. P. A. (1995). The effect of prior knowledge activation on text recall: An investigation of two conflicting hypotheses. British Journal of Educational Psychology, 65(4), 409-423.

Mayer, R. E. (1980). Elaboration techniques that increase the meaningfulness of technical text: An experimental test of the learning strategy hypothesis. Journal of Educational Psychology, 72(6), 770-784.

Mayer, R. E. (1985). Structural analysis of science prose: Can we increase problem-solving performance? In B. K. Britton \& J. B. Black (Eds.), Understanding expository text: A theoretical and practical handbook for analyzing explanatory text. Hillsdale, NJ: Erlbaum.

McDonald, B. A., Larson, C. O., Dansereau, D. F., \& Spurlin, J. E. (1985). Cooperative dyads: Impact on text learning and transfer. Contemporary Educational Psychology, 10(4), 369-377.

Moust, J. H. C., Schmidt, H. G., De Volder, M. L., Belien, J. J., \& De Grave, W. S. (1987). Effects of verbal participation in small group discussion. In J. T. E. Richardson, M. W. Eysenck, \& D. W. Piper (Eds.), Student learning: Research in education and cognitive psychology (pp. 147-154). Guildford Maidenhead, BRK England: Society for Research into Higher Education, Open University Press.

O'Donnell, A. M. (1996). Effects of explicit incentives on scripted and unscripted cooperation. Journal of Educational Psychology, 88(1), 74-86.

O’Donnell, A. M. (2006). The role of peers and group learning. In P. H. Winne \& P. A. Alexander (Eds.), Handbook of educational psychology (pp. 781-802). Mahwah, NJ: Erlbaum.

O’Donnell, A. M., Dansereau, D. F., Rocklin, T. R., Hythecker, V. I., Lambiotte, J. G., Larson, C. O., et al. (1985). Effects of elaboration frequency on cooperative learning. Journal of Educational Psychology, 77(5), 572-580.

Peeck, J. (1982). Effects of mobilization of prior knowledge on free recall. Journal of Experimental Psychology: Learning Memory and Cognition, 8(6), 608-612.

Pressley, M., McDaniel, M. A., Turnure, J. E., Wood, E., \& Ahmad, M. (1987). Generation and precision of elaboration: Effects on intentional and incidental learning. Journal of Experimental Psychology: Learning Memory and Cognition, 13(2), 291-300.

Pressley, M., Symons, S., McDaniel, M. A., Snyder, B. L., \& Turnure, J. E. (1988). Elaborative interrogation facilitates acquisition of confusing facts. Journal of Educational Psychology, 80(3), 268-278.

Pressley, M., Tanenbaum, R., McDaniel, M. A., \& Wood, E. (1990). What happens when university students try to answer prequestions that accompany textbook material? Contemporary Educational Psychology, 15(1), 27-35. 
Reder, L. M. (1980). The role of elaboration in the comprehension and retention of prose: A critical review. Review of Educational Research, 50(1), 5-53.

Rewey, K. L., Dansereau, D. F., Skaggs, L. P., Hall, R. H., \& Pitre, U. (1989). Effects of scripted cooperation and knowledge maps on the processing of technical material. Journal of Educational Psychology, 81(4), 604-609.

Schmidt, H. G. (1984). Activatie van voorkennis en tekstverwerking/Activation of prior knowledge and text processing. Nederlands Tijdschrift voor de Psychologie en haar Grensgebieden, 39(6), 335-347.

Schmidt, H. G. (1993). Foundation of problem-based learning: Some explanatory notes. Medical Education, 27(5), 422-432.

Schmidt, H. G., De Volder, M. L., De Grave, W. S., Moust, J. H. C., \& Patel, V. L. (1989). Explanatory models in the processing of science text: The role of prior knowledge activation through small-group discussion. Journal of Educational Psychology, 81(4), 610-619.

Schmidt, H. G., Van der Molen, H. T., Te Winkel, W. W. R., \& Wijnen, W. H. F. W. (2009). Constructivist, problem-based learning does work: A meta-analysis of curricular comparisons involving a single medical school. Educational Psychologist, 44(4), 227-249.

Slavin, R. E., Hurley, E. A., \& Chamberlain, A. (2003). Cooperative learning and achievement: Theory and research. In G. E. Miller \& W. M. Reynolds (Eds.), Handbook of psychology: Educational psychology (Vol. 7, pp. 177-198). Hoboken, NJ: Wiley.

Spurlin, J. E., Dansereau, D. F., Larson, C. O., \& Brooks, L. W. (1984). Cooperative learning strategies in processing descriptive text: Effects of role and activity level of the learner. Cognition and Instruction, 1(4), 451-463.

Tans, R. W., Schmidt, H. G., Schade-Hoogeveen, B. E., \& Gijselaers, W. H. (1986). Sturing van het onderwijsleerproces door middel van problemen: een veldexperiment/Problem-based learning: A field experiment. Tijdschrift voor Onderwijsresearch, 11(1), 35-46.

Van Boxtel, C., Van der Linden, J., \& Kanselaar, G. (2000). Collaborative learning tasks and the elaboration of conceptual knowledge. Learning and Instruction, 10, 311-330.

Webb, N. M. (1989). Peer interaction and learning in small groups. International Journal of Educational Research, 13(1), 21-39.

Webb, N. M., \& Farivar, S. (1999). Developing productive group interaction in middle school mathematics. In A. M. O’Donnell \& A. King (Eds.), Cognitive perspectives on peer learning (pp. 117-149). Mahwah, NJ: Erlbaum.

Webb, N. M., Franke, M. L., Ing, M., Chan, A., De, T., Freund, D., et al. (2008). The role of teacher instructional practices in student collaboration. Contemporary Educational Psychology, 33(3), 360-381.

Webb, N. M., Nemer, K. M., Chizhik, A. W., \& Sugrue, B. (1998). Equity issues in collaborative group assessment: Group composition and performance. American Educational Research Journal, 35(4), $607-651$.

Webb, N. M., Troper, J. D., \& Fall, R. (1995). Constructive activity and learning in collaborative small groups. Journal of Educational Psychology, 87(3), 406-423.

Wetzels, S. A. J., Kester, L., \& Van Merriënboer, J. J. G. (2011). Adapting prior knowledge activation: Mobilisation, perspective taking, and learners' prior knowledge. Computers in Human Behavior, 27(1), $16-21$.

Willoughby, T., Waller, T. G., Wood, E., \& MacKinnon, G. E. (1993). The effect of prior knowledge on an immediate and delayed associative learning task following elaborative interrogation. Contemporary Educational Psychology, 18(1), 36-46.

Wittrock, M. C. (1992). Generative learning processes of the brain. Educational Psychologist, 27(4), 531-541.

Woloshyn, V. E., Pressley, M., \& Schneider, W. (1992). Elaborative-interrogation and prior-knowledge effects on learning of facts. Journal of Educational Psychology, 84(1), 115-124. 